\title{
Short communication: Herd-level variables associated with overmilking in Michigan dairy herds
}

\author{
R. Moore-Foster, ${ }^{1}$ B. Norby, ${ }^{1}$ R. L. Schewe, ${ }^{2}$ R. Thomson, ${ }^{3}$ P. C. Bartlett, ${ }^{1}$ and R. J. Erskine ${ }^{1 *}$ \\ ${ }^{1}$ Department of Large Animal Clinical Sciences, Michigan State University, East Lansing 48824 \\ 2Department of Sociology, Syracuse University, Syracuse, NY 13244 \\ ${ }^{3}$ Department of Animal Science, Michigan State University, East Lansing 48824
}

\section{ABSTRACT}

The objective of this study was to determine the herd-level variables that are associated with overmilking in 64 Michigan dairy herds with a mean herd size of 451 cows (range: 59-2,771 cows). Participating producers completed surveys to indicate their mastitis management practices and attitudes. Additionally, milking protocols were observed and milk flow dynamics for 3,824 cows were estimated using digital vacuum recorders. The median duration of overmilking was $47 \mathrm{~s}(95 \%$ confidence interval, CI: 38.6 to 55.9 s), with a mean of $55 \%$ (95\% CI: 49.5 to $61.1 \%$ ) of cows within each herd overmilked by at least $30 \mathrm{~s}$. Median milking time for all herds was 324 s (95\% CI: 302 to 346 s) and was found to be positively correlated with median duration of overmilking $(\mathrm{r}=0.670)$. Backward multivariate analysis was used to determine which of 45 herd-level milking and management variables were associated with median duration of overmilking. Median duration of overmilking was negatively associated with the duration of time needed to complete 1 milking for the entire herd (adjusted $\mathrm{R}^{2}=0.13$ ). Herds that operate milking facilities below maximum daily capacity may be prone to overmilking. Given the low coefficient of determination, variables unaccounted for in this study, such as equipment function or manual detachment by milking operators, are likely the most important risk factors for overmilking.

Key words: overmilking, milking protocol, labor management

\section{Short Communication}

Overmilking (OVM) occurs when milk flow to the teat cistern is less than the flow out of the teat canal (Rasmussen, 2004). This can be caused by improper settings for automatic cluster removers (ACR) that

Received February 12, 2019.

Accepted May 8, 2019.

*Corresponding author: erskine@msu.edu detach from the teats after extended periods of low milk flow, subjective manual removal of clusters by milking personnel, or reattachment of clusters after milking is complete. Overmilking results in longer milking times (duration of milking unit attachment) and greater duration of teat ends to vacuum (Rasmussen, 2004). Short-term effects of OVM on teats include skin discoloration (congestion), ringing at the base of the teat, and edema (Hillaerton et al., 2002; Rasmussen, 2004). As OVM causes longer milking times, long-term effects of OVM are an increased risk for roughness or hyperkeratosis of teat ends, especially if OVM periods are >2 min (Neijenhuis et al., 2000; Rasmussen, 2004; Edwards et al., 2013).

Moderate and severely hyperkeratotic teat ends have a higher risk of clinical mastitis than normal teats ends (Neijenhuis et al., 2001; Breen et al., 2009). Tančin et al. (2007) reported that quarters with high SCC $(>500$ $\times 10^{3}$ cells $/ \mathrm{mL}$ ) had longer OVM phases of milk flow compared with quarters with low SCC $\left(<200 \times 10^{3}\right.$ cells $/ \mathrm{mL}$ ). In addition to changes in teat health and subsequent risk of mastitis, increased milking time from OVM decreases parlor capacity and efficiency.

Despite knowledge of the deleterious effects and causes of OVM, little is known of farm workforce and related herd management variables that may be associated with the frequency of OVM. As herd size increases in the US dairy industry, farms are increasingly reliant on hired labor (Baker and Chappelle, 2012; von Keyserlingk et al., 2013), and the effect of the labor culture on milking efficiency is largely unknown. Thus, the primary objective of this study was to determine the herd-level variables, including the labor culture, associated with OVM.

Because the vacuum in the liner mouthpiece chamber $\left(\mathbf{V}_{\text {MPC }}\right)$ is strongly and negatively correlated with milk flow rate (Borkhus and Rønningen, 2003; Penry et al., 2018), we had previously applied this concept in a field study of more than 3,800 cows to determine herd-level variables associated with delayed milk ejection (MooreFoster et al., 2019a). Thus, we wanted to further investigate the use of milking unit vacuum, specifically $\mathrm{V}_{\mathrm{MPC}}$ 
and vacuum in the short milk tube $\left(\mathbf{V}_{\mathbf{S M T}}\right)$, to identify the prevalence and possible explanatory variables of OVM in 64 Michigan dairy herds between January 2016 and May 2017.

Mean herd size was 451 (median: 294) milking cows, ranging from 59 to 2,771 cows, and $97 \%(62 / 64)$ of herds milked with ACR. Herds that milked with automated milking systems were excluded.

For each herd, we recorded milking times and groups, type of milking facility, housing, employee structure, and other information related to mastitis control (e.g., use of dry cow therapy). To determine the labor culture, we interviewed dairy producers and managers to attain their perspective on herd mastitis control practices and attitudes. The questions from this survey were previously published (Moore-Foster et al., 2019a). All survey information was approved by the Institutional Review Board of Michigan State University.

Additionally, we conducted a milk quality evaluation for each herd that included (1) milking procedures, (2) milking systems, (3) cow environment, (4) monitoring and therapy of infected cows, and (5) farm labor culture. Further details of the evaluation have been previously reported (Moore-Foster et al., 2019a).

During the evaluation of milking procedures, we determined the milking routine (e.g., the number of passes to each cow) and the time interval between each preparation step as previously described (Moore-Foster et al., 2019a). Additionally, we evaluated milking vacuum from 3,824 cows (mean of $60 \pm$ standard error of 29 recordings per herd) with VaDia digital recorders (Biocontrol, Rakkestad, Norway). We recorded vacuum on the following positions of the milking cluster: (1) rear quarter liner mouthpiece chamber, (2) front quarter mouthpiece chamber, (3) short milk tube, and (4) short pulsation tube. All vacuum recordings were downloaded and then reviewed using the VaDia Suite software (Biocontrol, Rakkestad, Norway).

We used the methods of Moore-Foster et al. (2019a) to estimate key events in the phases of milk flow. We determined these events by manual evaluation of data tracings rather than the default settings of the VaDia Suite software. For consistency, only 2 investigators (R. M.-F. and R. J. E.) conducted the parlor evaluations and vacuum analysis. For each cow, OVM was determined to begin when $\mathrm{V}_{\mathrm{MPC}}$ in both channels increased and reached a plateau above $15 \mathrm{kPa}$ and the range of $\mathrm{V}_{\mathrm{SMT}}$ fluctuations narrowed to $<3 \mathrm{kPa}$. The end of milking was determined to occur when vacuum returned to $0 \mathrm{kPa}$ (see Figure 1). Thus, the duration of OVM was the time interval between the start of OVM and the end of milking. The median duration of the OVM period across all herds was 47 s (95\% CI: 38.6 to 55.9 s), with a mean of $55 \%$ (95\% CI: 49.5 to $61.1 \%$ ) of cows within each herd overmilked by at least $30 \mathrm{~s}$. Median milking time for all herds was 324 s (95\% CI: 302 to $346 \mathrm{~s}$ ) and was found to be positively correlated with median period of OVM $\left(r=0.67 ; \mathrm{R}^{2}=0.45\right)$.

The dependent variable was median OVM period, which was selected rather than mean OVM after reviewing the skewed distribution of the duration of OVM for all cows included in the study (Figure 2). All data were entered into Microsoft Excel (Microsoft Corp., Redmond, WA) for data management and imported into SAS (version 9.4; SAS Institute Inc., Cary, NC) for descriptive and analytical statistical analyses.

As described in Moore-Foster et al. (2019a), independent variables were divided into 3 categories: (1) labor culture and human resources, (2) milking operator procedures, and (3) parlor factors. We defined milking operators as any personnel who milked cows, including employees and owners. Labor culture and human resource variables included operator turnover rates (defined as number of operators hired per year divided by number of positions available), frequency of employee training, manager attitudes about parlor turnover rates, and how often managers communicate with employees on personal matters. Operator procedures included premilking preparation protocols, the workload of operators (e.g., the number of milking units per operator and cows milked per operator per hour), the duration of employee shift length (defined as milking shift duration), and the proportion of cow milkings with units reattached after milking was complete (as determined by VaDia analysis). Parlor factors included rail height, illumination, frequency of milkings per day, whether $95 \%$ of liners were properly aligned (yes $=1$, no $=0$ ), and whether $95 \%$ of air vents on the cluster were patent (yes $=1$, no $=0$ ).

Initially, a frequency distribution was set up for each independent variable in our model and normality was checked. We performed principal component factor analysis to determine whether it was appropriate to combine independent variables into composite scales or factors relative to management attitudes and beliefs regarding labor. However, alpha values and Eigenvalues were not significant (Eigenvalue $>1$ and Cronbach's $\alpha$ $>0.7)$ for all of the scales.

Continuous independent variables that were right skewed were log transformed before bivariate analysis to attain normality. To decide which independent variables should be included for multivariate analysis, associations between median OVM and explanatory continuous variables were investigated using Pearson's product-moment correlation coefficient using SAS (version 9.4; SAS Institute Inc.). For binary (nominal) variables, the dependent variable was compared with independent variables using an adjusted Wald test for 


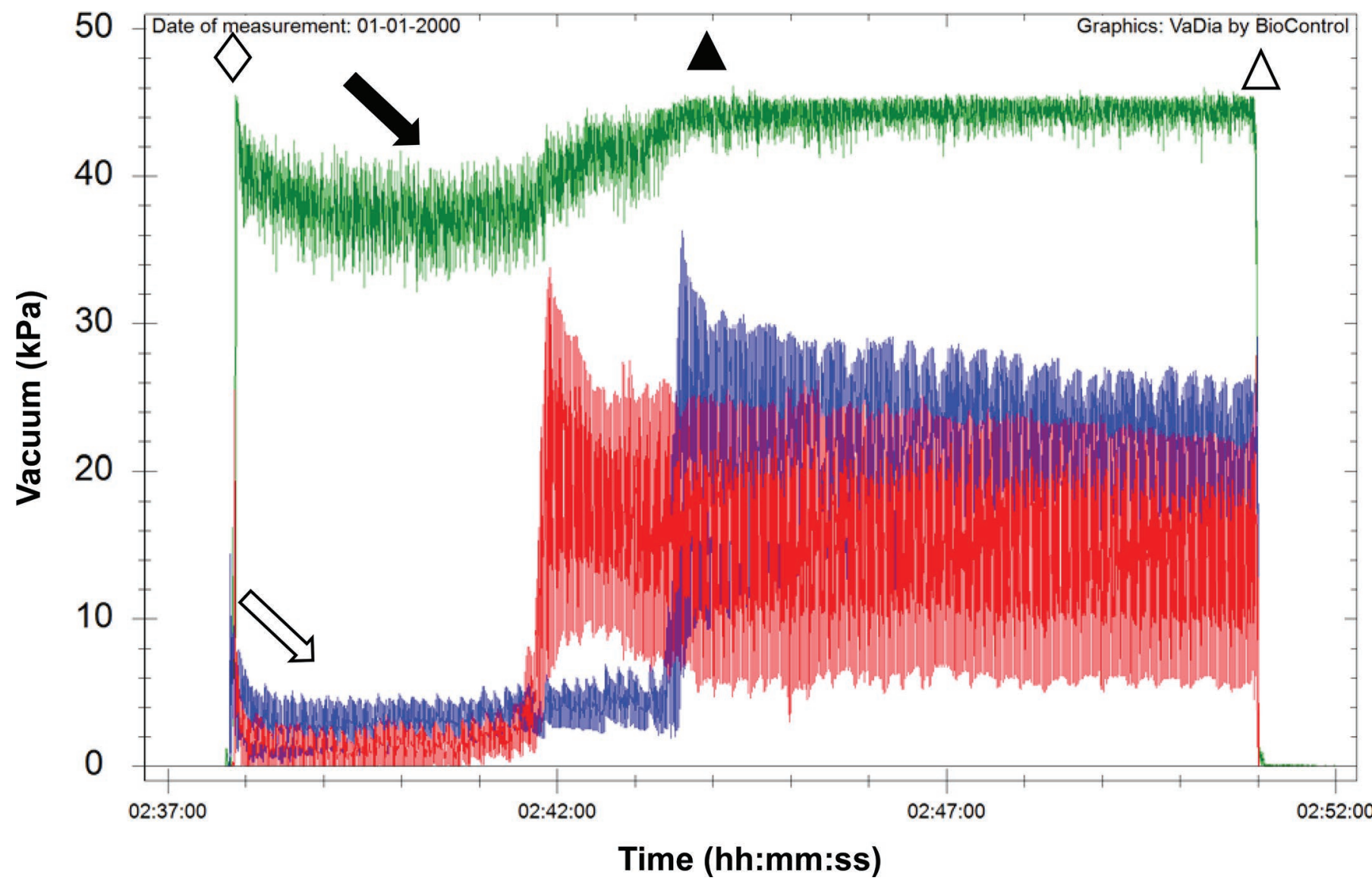

Figure 1. Example of digital vacuum recording demonstrating overmilking. The vertical axis indicates vacuum ( $\mathrm{kPa}$ ). The horizontal axis indicates time after cluster attachment divided into 1-min intervals. Channels 1 and 2 (white arrow, red and blue lines) represent the rear and front mouthpiece chambers, respectively, and channel 3 (black arrow, green line) represents the short milk tube. Symbols mark the start of milking $(\diamond)$, start of overmilking $(\boldsymbol{\Lambda})$, and end of milking $(\Delta)$.

significance of the relationship. Any variables with an initial cutoff of $P<0.20$ (2-tails) were considered eligible for inclusion in the multivariable model.

Based on the bivariate analysis, 7 variables were significantly and negatively correlated with median OVM: herd size, milking shift duration, frequency of milking, milk produced by the herd per day, total distance operators walk while milking per milking shift, duration of work break for employees, and hours of milking facility operation per day. Conversely, annual employee turnover rate and variability in premilking protocols (as measured by standard deviation in teat stimulation) were positively correlated with median OVM. Additionally, patency of air vents (as a categorical variable described above) was positively associated with median OVM. The positive association between air vent patency and OVM is counterintuitive (i.e., poor air admission into the cluster impairs efficient removal of milk from the cluster). This in turn would increase milking times and OVM. However, a possible confounder with this result may be that herds that do not prioritize maximum parlor utilization may have a time budget that allows the completion of other tasks, such as more frequent cleaning of the milking units.

Using multiple regression and the type-III $F$-test, an automated backward-stepwise elimination procedure was used to build the final multivariable model until only significant covariates $(P<0.05)$ were retained. Interactions were also analyzed; however, no significance was found. The residual distribution was assessed visually for normality and homoscedasticity. The final multivariable model found only milking shift duration to be significantly and negatively associated with median OVM (Table 1).

In our study, mean $\mathrm{V}_{\mathrm{MPC}}$ for individual cows during the OVM period was typically $>27 \mathrm{kPa}$, which indicates that milk flow is low or nonexistent. Subsequently, lack of milk-derived positive pressure within the teat cistern results in the teat barrel becoming thinner and a poor seal between the teat and liner wall (Borkhus and Rønningen, 2003). This alters the depth of teat penetration into the barrel of the liner, which in turn increases leak- 


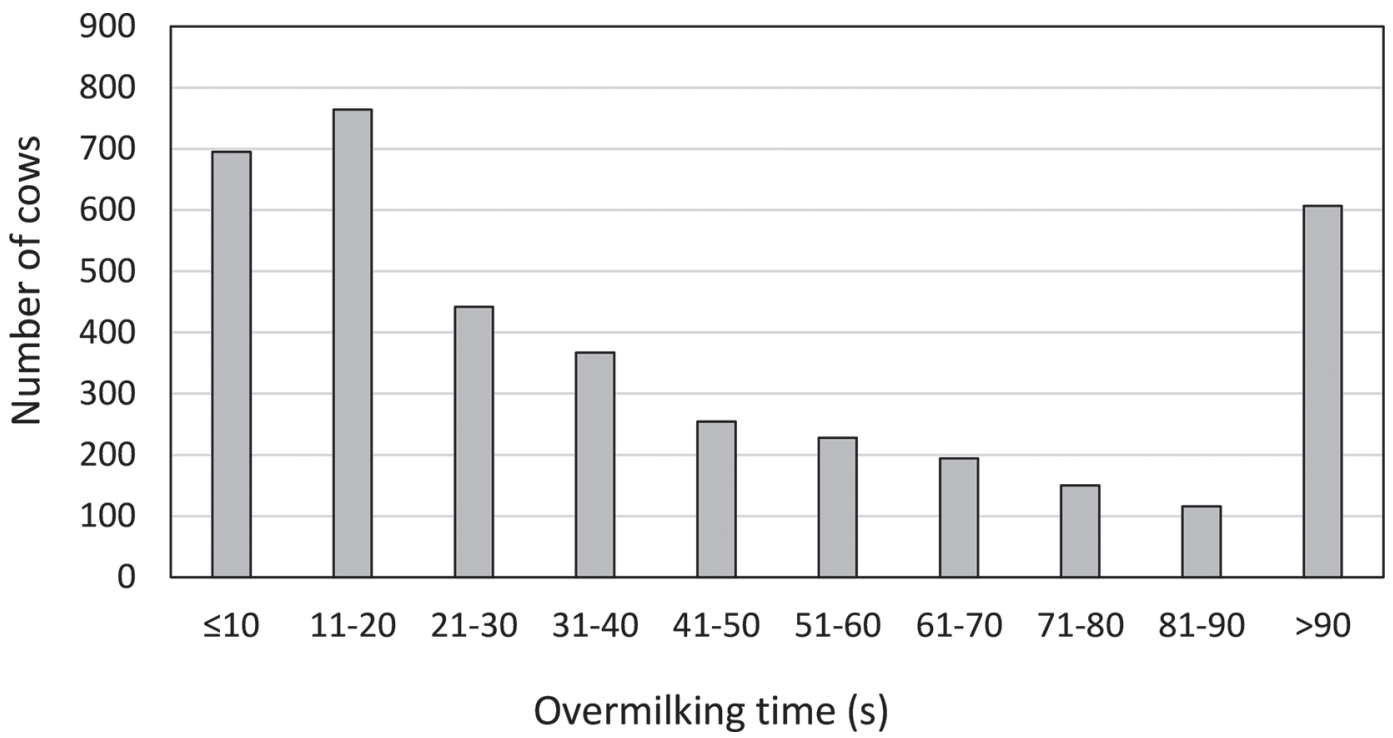

Figure 2. Histogram of duration of overmilking ( $\mathrm{s}$ ) of individual animals in 64 Michigan dairy herds as recorded by digital vacuum (n = 3,824 cows).

age of milking vacuum into the mouthpiece chamber from the teat end, thus increasing $\mathrm{V}_{\mathrm{MPC}}$ (Borkhus and Rønningen, 2003). As the duration of OVM increases, the liner mouthpiece forms a seal at the base of the teat, constricts the cricoid (annular) ring, and impedes milk flow between the gland and teat cistern (Borkhus and Rønningen, 2003). This results in insufficient removal of blood and interstitial fluids so that congestion and edema occur (Paulrud et al., 2005). Taken together, increased $\mathrm{V}_{\mathrm{MPC}}$ during OVM negatively affects overall teat health.

As median OVM across all herds was $>45 \mathrm{~s}$, this suggests that many herds have an opportunity to increase milking efficiency by decreasing OVM. Our model found that shorter milking shifts are associated with increased periods of OVM. However, given the low coefficient of determination, there are likely important unaccounted variables in our model. For example, OVM may occur if ACR are not properly maintained or if detachment is set to a low milk rate threshold. The majority $(78 \%)$ of the herds in this study stated that they had a protocol or schedule for milking equipment maintenance, and $83 \%$ of the herds evaluated their entire milking system at least once a year. Anecdotally, many producers believe

Table 1. Final linear model for associations between median overmilking time and herd-level variables in 64 Michigan dairies

\begin{tabular}{|c|c|c|c|c|}
\hline Parameter & Estimate & $\mathrm{SE}$ & $P$-value & $\mathrm{R}^{2}$ \\
\hline $\begin{array}{l}\text { Intercept } \\
\text { Milking shift }{ }^{1} \\
\text { duration }(\mathrm{h})\end{array}$ & $\begin{array}{r}1.78 \\
-0.04\end{array}$ & $\begin{array}{l}0.08 \\
0.01\end{array}$ & $\begin{array}{r}<0.0001 \\
0.0035\end{array}$ & 0.13 \\
\hline
\end{tabular}

\footnotetext{
${ }^{1}$ The time interval of an employee's shift.
}

that their routine equipment maintenance programs do not include ACR service and are unaware of the milk flow thresholds for their ACR. We did not assess ACR performance; therefore, this remains an important and unaccounted variable in our study.

Due to the scope of our milking evaluations, it was difficult to track an accurate proportion of cow milkings that the operators set to manual cluster removal. Frequency of manual removal was variable between and within herds, with the criteria for cow selection based on perceived slow milk flow, nervous behavior, and appearance of the udder.

Our findings could reflect an attitude among operators with shorter milking shifts that there is less pressure to stay on schedule to finish milking before the next milking shift begins. Herds that do not maximize the capacity of their milking facility may allow employees more latitude to subjectively assess whether milk is present in the udder and make the decision to continue milking. This concept is supported by an Irish study (O'Brien et al., 2012) that found that operator idle time decreases as parlor size (number of units) increases. Although our final model included lower parlor capacity as an explanatory variable for increased OVM, it was interesting to note that variables that indicated higher parlor throughput (e.g., longer shift duration and increased milking frequency) were found to be associated with decreased OVM on bivariate analysis.

Previous research has found that as farm size increases, less time is spent on udder preparation, resulting in higher frequencies of delayed milk ejection (Sandrucci et al., 2007; Moore-Foster et al., 2019b). This presents an intriguing dynamic, suggesting that as herds try to 
increase parlor throughput, less preparation is given to each cow, resulting in more bimodal milking. But herds that do not emphasize parlor throughput may be more susceptible to OVM. Both of these potential problems with milking efficiency are often related to operator procedures.

Even if ACR are functioning, OVM can occur when operators reattach ACR-removed clusters. We found no association between the percentage of cows that were reattached in each herd and median OVM time. The range of cows within each herd that were reattached was 0 to $8.9 \%$. However, the frequency of reattached cows was highly skewed (data not shown), the median was $1.3 \%$, and 54 of 64 herds had $\leq 3 \%$ of cows reattached. Thus, our herd sample size may have lacked the power to discriminate the effect of this variable on OVM.

This study had several limitations. We used vacuum to identify key changes in the phases of the milking curve, not a quantitative measure of milk flow. The sample size of cows averaged about $23 \%$ of the herd but varied depending on herd size, the duration of the milking shift, and the time period when investigators were present during milking. In smaller herds, (milking shifts $<4 \mathrm{~h}$ ) we were present throughout the entire milking. However, it was difficult to evaluate all employees and milking groups for all shifts. This was especially true in larger herds. When we were unable to attend an entire milking shift for a herd, we recorded milkings in portions of at least 2 employee shifts and several milking groups. Also, we placed multiple vacuum recorders at diverse milking positions in each parlor to capture variation between individual milking operators. Individual cow variables were not measured in this study, including stage of lactation, mastitis, genetics, teat anatomy, and parity. Finally, we recorded $\mathrm{V}_{\mathrm{MPC}}$ for only 2 of 4 liners, not accounting for possible continued milk flow in other quarters after we determined OVM. We believe our interpretation was bolstered from a consistent approach to analysis and by including $\mathrm{V}_{\mathrm{SMT}}$ in the criteria for OVM. However, this too has limitations because the difference between average $\mathrm{V}_{\mathrm{SMT}}$ when all 4 quarters are in milk flow and no milk flow may be quite low for some cows. Thus, deciding that OVM occurred during time periods when the range of $\mathrm{V}_{\mathrm{SMT}}$ was $<3 \mathrm{kPa}$ may have not offered enough discrimination.

Herds that use milking facilities under full daily capacity are more likely to overmilk cows. It is important to ensure that ACR are well maintained and that milking operators are trained to either correctly determine when milking is complete or rely on ACR. Increased
OVM is correlated with increased milking time, thus decreasing milking and parlor efficiency.

\section{ACKNOWLEDGMENTS}

This project was supported by Agriculture and Food Research Initiative Competitive Grant no. 2013-6800420439 from the USDA National Institute of Food and Agriculture (Washington, DC). We thank the participating herds and their employees.

\section{REFERENCES}

Baker, D., and D. Chappelle. 2012. Health status and needs of Latino dairy farmworkers in Vermont. J. Agromedicine 17:277-287.

Borkhus, M., and O. Rønningen. 2003. Factors affecting mouthpiece chamber vacuum in machine milking. J. Dairy Res. 70:283-288.

Breen, J. E., M. J. Green, and A. J. Bradley. 2009. Quarter and cow risk factors associated with the occurrence of clinical mastitis in dairy cows in the United Kingdom. J. Dairy Sci. 92:2551-2561.

Edwards, J. P., B. O'Brien, N. Lopez-Villalobos, and J. G. Jago. 2013. Overmilking causes deterioration in teat-end condition of dairy cows in late lactation. J. Dairy Res. 80:344-348.

Hillaerton, J. E., J. W. Pankey, and P. Pankey. 2002. Effect of overmilking on teat condition. J. Dairy Res. 69:81-84.

Moore-Foster, R., B. Norby, R. L. Schewe, R. Thomson, P. C. Bartlett, and R. J. Erskine. 2019a. Herd-level variables associated with delayed milk ejection in Michigan dairy herds. J. Dairy Sci. 102:696705.

Moore-Foster, R., B. Norby, R. L. Schewe, R. Thomson, P. C. Bartlett, and R. J. Erskine. 2019b. Herd-level variables associated with premilking stimulation time in Michigan dairy herds. J. Dairy Sci. 102:2544-2550.

Neijenhuis, F., H. W. Barkema, H. Hogeveen, and J. P. T. M. Noordhuizen. 2000. Classification and longitudinal examination of callused teat ends in dairy cows. J. Dairy Sci. 83:2795-2804.

Neijenhuis, F., H. W. Barkema, H. Hogeveen, and J. P. T. M. Noordhuizen. 2001. Relationship between teat-end callosity and occurrence of clinical mastitis. J. Dairy Sci. 84:2664-2672.

O'Brien, B., J. Jago, J. P. Edwards, N. Lopez-Villalobos, and F. McCoy. 2012. Milking parlour size, pre-milking routine and stage of lactation affect efficiency of milking in single-operator herringbone parlours. J. Dairy Res. 79:216-223.

Paulrud, C. O., S. Clausen, P. E. Andersen, and M. D. Rasmussen. 2005. Infrared thermography and ultrasonography to indirectly monitor the influence of liner type and overmilking on teat tissue recovery. Acta Vet. Scand. 46:137-147.

Penry, J. F., J. Upton, S. Leonardi, P. D. Thompson, and D. J. Reinemann. 2018. A method for assessing liner performance during the peak milk flow period. J. Dairy Sci. 101:649-660.

Rasmussen, M. D. 2004. Overmilking and teat condition. Pages 169 175 in Proc. 43rd Ann. Mtg. Natl. Mastitis Council, Charlotte, NC. National Mastitis Council, New Prague, MN.

Sandrucci, A., A. Tamburini, L. Bava, and M. Zucali. 2007. Factors affecting milk flow traits in dairy cows: Results of a field study. J. Dairy Sci. 90:1159-1167.

Tančin, V., A. H. Ipema, and P. Hogewerf. 2007. Interaction of somatic cell count and quarter milk flow patterns. J. Dairy Sci. 90:22232228.

von Keyserlingk, M. A., N. P. Martin, E. Kebreab, K. F. Knowlton, R. J. Grant, M. Stephenson, C. J. Sniffen, J. P. Harner 3rd, A. D. Wright, and S. I. Smith. 2013. Invited review: Sustainability of the US dairy industry. J. Dairy Sci. 96:5405-5425. 